\title{
Precise of The Contents of Visual Experience
}

\section{Citation}

Siegel, Susanna C. 2013. "Precise of The Contents of Visual Experience." Philosophical Studies 163 (3) (April): 813-816. doi:10.1007/s11098-012-0014-5. http://dx.doi.org/10.1007/ s11098-012-0014-5.

\section{Published Version}

doi:10.1007/s11098-012-0014-5

\section{Permanent link}

http://nrs.harvard.edu/urn-3:HUL.InstRepos:11879947

\section{Terms of Use}

This article was downloaded from Harvard University's DASH repository, and is made available under the terms and conditions applicable to Open Access Policy Articles, as set forth at http:// nrs.harvard.edu/urn-3:HUL.InstRepos:dash.current.terms-of-use\#OAP

\section{Share Your Story}

The Harvard community has made this article openly available.

Please share how this access benefits you. Submit a story.

Accessibility 
Precis of The Contents of Visual Experience, by Susanna Siegel.

2010, Oxford University Press (all page numbers refer to the book).

Forthcoming in a book symposium in Philosophical Studies, with comments by John

Campbell, Jesse Prinz and Charles Travis.

If you look out at the street through the window and see pedestrians and bicyclists and cars and dogs making their way from one part of the scene to another, what exactly are you visually conscious of? According to the Rich Content View, there is more present in visual experience than just color, shape, illumination, motion and other spatial properties. The Contents of Visual Experience is a defense of the Rich Content View.

Since the Rich Content View is a thesis about the contents of experience, if experiences have no contents, then the Rich Content View is false. But something like the Rich Content View could be formulated, independently of the assumption that experiences have contents. For instance, in the framework of traditional adverbialism, we could ask: in what ways may we be appeared-to? Or if perceptual experiences are relations to individual things (such as John Malkovich) and their properties, then we can still ask: which properties may we be perceptually related to? Just colors and shapes, or kinds and causation as well? (cf p. 97 where this point is first made). Speaking more abstractly, we can state the issue behind the Rich Content View by asking which properties we can be presented with in experience. In pursuing this issue, however, we have to face the question of what being presented with properties amounts to. The notion of presentation has to be pinned down, to make the issue behind the Rich Content View tractable. I pin it down by arguing that being presented with properties in experience ultimately amounts to the experience having contents.

What is it for experiences to have contents? And what exactly are visual experiences in the first place? Let's start with visual experiences. Suppose you are seeing someone (call him Franco) while he is curled up in a chair. Franco is curled up in a chair right now, but later on he'll get up, you'll see him again, and he'll look different - upright instead of sitting, walking instead of being still, awake instead of asleep. Is your state of seeing Franco - the one you're in both times - an experience? Or is the only type of experience in the picture ones that are individuated by what it's like for you to see Franco on each of these occasions? Both states are natural to call "visual experiences", but I tie my primary use of "experience" to phenomenal states, which are individuated by what it's like to be in them. The Rich Content View is a thesis about phenomenal states.

What is it for experiences to have contents? Contents of experiences are a type of accuracy condition. If experiences have contents, then experiences can be accurate or inaccurate, and they are accurate if their contents are true. Would any old accuracy condition of an experience be a content of that experience? Consider the condition of being accurate, which every accurate experience has in common. If all there were to the notion of content was that contents determine accuracy conditions, then an experience 
could count as having content, simply by being such that it is accurate or inaccurate without there being any further facts about which contents it has. This result would not be trivial, but the notion of content it uses would not tell us much about the role of contentful experiences in the mind. My notion of experience contents gets some of its substance from the constraint that contents have to be conveyed to the subject. A content is conveyed by being available for at least one of three functions: guiding action, belief-formation, and introspection.

It is controversial whether experiences have contents. I argue that they do, by defending the Content View, which is the thesis that all visual perceptual experiences have contents. Since experiences are phenomenal states, the Content View is a thesis about phenomenal states. More exactly, it is a thesis about your average visual experiences, typified by the kind you have when you are seeing ordinary objects and scenes. Visual perceptual experiences exclude visual experiences involved in phosphenes (when you gently press your eyeball), the brain grey that you get sometimes when your eyes are closed, as well as the pink glow that appears when you close your eyes in bright light.

Writ large, my argument for the Content View is that properties are presented in visual experience, and if they are so presented, then the experiences that present them have contents which derive from those properties. In this argument - which I call the Argument from Appearing - the key transition moves from a property $\mathrm{F}$ figuring in the phenomenal character of an experience, to $\mathrm{F}$ figuring in the content of that experience. Since the contents of experience derive properties presented in experience, those contents reflect the phenomenal character of experience (p. 6, p. 78). I discuss a range of challenges to the various steps in this argument, including the challenge (suggested by Travis (2004)) that denies that properties are presented in experience, and the challenge (suggested by Campbell (2002) and other Naïve Realists) that if experiences are fundamentally perceptual relations, then they do not have contents. ${ }^{1}$

At the heart of my discussion, the Content View plays an instrumental role, by providing a tractable way to formulate the idea behind the Rich Content View. There are thus two orthogonal debates: one over the Content View, the other concerning which properties we can be presented with in experience.

How can we determine whether the Rich Content View is true? I defend and employ a method of phenomenal contrast, which is a way to test specific hypotheses about what we experience. The method is to isolate a phenomenal contrast that a target hypothesis about the properties presented in experience would purport to explain, and then see whether that hypothesis provides the best explanation of that contrast. So instead of taking a specific visual experience as input and delivering a verdict on its contents (or

${ }^{1}$ C. Travis (2004) "The Silence of the Senses". Mind 113 (449): 57-94, J. Campbell (2002), Reference and Consciousness. Oxford University Press. 
the properties it presents) as an output, the method's starting point is a target hypothesis, and it aims to reach a yes-or-no verdict on that hypothesis through abduction. The contrast method provides a structure that is independent of specific hypotheses that it can test. Which alternative explanations need to be considered, and the considerations that are relevant to them, will depend on the target hypothesis, and will vary from case to case.

I apply the contrast method to three theses that are each more specific than the Rich Content View, but that each entail it: the thesis that kind properties are represented in experience (Chapter 4); the thesis that causal properties are represented in experience (Chapter 5); and the thesis that certain perceptual relations are represented in experience (Chapter 7). The contrast method itself is not specific to the Rich Content view, and nothing limits its application to phenomenal contrasts that are even putatively explained by the Rich Content Thesis. It is thus not the method that posits content differences or invokes rich contents to explain them, it is rather my application of the method to the Rich Content View using a trio of appropriate phenomenal contrasts. At its core, the method relies on introspection only to identify a phenomenal contrast between experiences. It thereby avoids the notorious difficulties of relying exclusively on introspection to determine the contents of the mind.

For each of the three theses about rich contents that I defend, the logical space of alternative explanations is the same: if the phenomenal contrast is not explained by a difference in rich contents, then it is explained in one of three other ways: (i) by a difference in non-rich contents, (ii) by a non-representational difference in visual experiences, or (iii) by a difference in non-visual experiences. A fourth option is that the putative phenomenal contrasts do not actually have that status - which brings out the fact that the existence of a phenomenal contrast is a starting point without which the contrast method cannot get off the ground. The considerations for and against each of these alternatives are different for each of the three theses I discuss. In this way, my defense of the Rich Content View comes in three separate modules, with the success of each one in principle independent of the fate of the other two.

The two central theses of the book, the Content View and the Rich Content View, are both theses about phenomenal states. However both can be extended to a wider range of states that are also natural to call "experiences". For instance, in addition to phenomenal states, there are phenomenally conscious states, such as the state of seeing Franco, which are states such that necessarily, in order to be in them, you have to be in a phenomenal state (p. 20). I argue that certain states of seeing, such as seeing Franco when he is sad and look sad, are phenomenally conscious, without being individuated by phenomenal character (and so without being phenomenal states), and I extend my argument for the Content View to these states of seeing. The key to the extension is that whereas phenomenal states present properties as instantiated, without taking a stand of which particular object has those properties, states of seeing do take a stand on which particular object has the properties presented in experience. States of seeing 
present certain objects (namely, those that are seen) as having certain properties; whereas phenomenal states simply present those properties as instantiated, without pinning down which object is doing the instantiating. A consecybequence of reapplying my argument from presentation to contents to these states of seeing is that these states have singular contents. For instance, your state of seeing Franco when he is sad and looks sad has contents that are true only if Franco is sad. Those contents could not be made true by anyone else other than Franco being sad. And when combined with my arguments that the properties that figure in rich contents can be presented in experience, a further upshot is that these states of seeing can have rich contents. 